\title{
Editorial
}

\section{Contabilidad y género, un camino por recorrer}

\author{
Gloria Milena Valero
}

Valero, G. M. (2020). Contabilidad y género, un camino por recorrer. Revista Activos, 18(2), 9-16. https://doi.org/10.15332/25005278/6239

Los estudios de género en las diferentes áreas disciplinares, profesionales o laborales llegaron para quedarse. Esta situación es muy valiosa porque resalta las dinámicas persistentes de segregación, falta de representación, subordinación, entre otros aspectos, que se han normalizado en las sociedades del mundo; pero que deben ser visibilizados e investigados de tal forma que dichas dinámicas no se vuelvan parte del paisaje. En ese orden de ideas, esta editorial tiene la intención de visibilizar las investigaciones desarrolladas alrededor de la temática de contabilidad y género en Colombia, las cuales se han gestado en la academia desde la investigación, tanto formal como formativa.

\footnotetext{
* Contadora Pública y Magíster en Medio Ambiente y Desarrollo de la Universidad Nacional de Colombia. Docente Líder de Investigación Facultad de Contaduría Pública de la Universidad Santo Tomás, Bogotá, Colombia. Correo electrónico: gloriavalero@usantotomas.edu.co ORCID: https://orcid.org/0000-0002-6796-3907
} 
Así, es preciso destacar lo señalado por Scott (2008) respecto a cómo "los estudios sobre las mujeres no sólo añadirían nuevos asuntos a tratar, sino que también forzarían un nuevo examen crítico de las premisas y los criterios existentes en los trabajos universitarios" (p. 50); sin perder de vista que los estudios de género abordan las distintas interacciones sociales entre mujeres y hombres, particularmente, "las relaciones simbólicas de poder" (Scott, 2008, p. 65).

Ahora bien, entre las investigaciones históricas que promueven los análisis desde las subjetividades femeninas, se encuentra el trabajo de Carmona, Ezzamel y Mogotocoro (2018) en el cual se examina el caso de la Marquesa de Valdehoyos durante 1760-1775 (una importante empresaria cartagenera miembro de la nobleza), y con base en su trayectoria se realiza un análisis detallado de su estilo de gestión en un contexto dominado por los hombres; esto contribuyó a identificar las condiciones que incidieron en su triunfo en un mundo empresarial marcadamente masculino.

En la misma línea, Rico (2020) explora la participación femenina en la historia contable colombiana desde la colonia hasta el siglo $\mathrm{xx}$, siguiendo el marco conceptual de J. Scott. Dicha exploración le permitió evidenciar representaciones simbólicas del quehacer contable de las mujeres en contextos como los conventos de la época colonial; la economía doméstica; y la educación primaria femenina decimonónica, así como su entrada al mercado de servicios profesionales. Al respecto, es relevante mencionar que el autor reivindica el trabajo y las actividades contables como un factor que contribuyó a que las mujeres "se emanciparan", ganando su independencia al alejarse de las actividades tradicionalmente establecidas según el género.

Por último, con relación a la participación de la mujer en el programa de Contaduría en la Universidad del Valle, se identifica un estudio descriptivo centrado en articular lo histórico con las percepciones actuales de las estudiantes y egresadas del programa y sobre su ejercicio profesional (Santana y Pastás, 2019). 
Con respecto a la investigación, se encuentran trabajos relacionados con la producción académica y el liderazgo de las mujeres contables del Departamento del Quindío adscritas a los grupos de investigación locales (López E. J, 2018). Así mismo, se hallan trabajos que intentan dar cuenta de los aportes, retos, perspectivas y experiencias de las contables colombianas en el medio académico e investigativo. Estos ejercicios se han realizado desde diferentes vías: por ejemplo, Patiño y Valero (2012) parten de la revisión de la base de datos del ahora Ministerio de Ciencias y Tecnología; Chamorro, Patiño y Vásquez (2020) lo hacen mediante entrevistas semiestructuradas; mientras Patiño, Valero, Acosta y Díaz (2021, en prensa) utilizan las encuestas a investigadoras latinoamericanas; en tanto, López D. (2018) hace una revisión de las publicaciones académicas realizadas por mujeres contadoras colombianas, principalmente, en las revistas Cuadernos de Contabilidad y Contaduría de la Universidad de Antioquia, evidenciando el uso de metodologías cualitativas en sus trabajos.

Adicionalmente, ante la ampliación en el número de revistas objeto de estudio, el trabajo de Chamorro (2015) explora un análisis diferencial sobre la participación femenina en los cargos de representación de la profesión contable. A su vez, García, Valero, Sandoval y Cortes (2021, en prensa) se centran en la participación femenina en el ámbito educativo contable a partir de una revisión documental en bases de datos académicas sobre investigaciones relacionadas con educación contable y género con corte en el 2018.

Desde la esfera del trabajo, las investigaciones abordan la discriminación salarial por género en el ejercicio profesional contable, como en el caso de los trabajos de Restrepo (2018), Restrepo e Isaza (2019) que evidencian "la existencia de un trato discriminatorio que pasó del $58.7 \%$ en 2008 al $65.3 \%$ en el 2012" (p. 548), situación que se explica por una mayor participación masculina en cargos públicos con mejor remuneración, y está relacionada con características culturales del contexto que inciden en un trato diferencial entre hombre y mujeres. Frente a las brechas salariales y laborales Ospina y Ramírez (2013) profundizan el tema en la ciudad de Pereira. 
De igual forma, Valero, Patiño y Vargas (2020) analizan dos categorías que surgen de las relaciones del trabajo y el género en el marco de la profesión contable en Colombia entre el 2001 y el 2018; aquellas son la feminilización, como el incremento numérico del número de mujeres en la profesión; y la feminización, como los efectos sociales producto del incremento de la participación femenina (Yannoulas, 2011). Este trabajo resalta las problemáticas propias de una profesión profundamente feminilizada que comienza a reflejar los aspectos negativos de la feminización (Bueno y León, 2013), entre ellos: que los hombres empiezan a desertar de la profesión por estar feminilizada; además, hay evidencias de que la participación femenina en las actividades laborales contribuye a la reducción de los salarios y del estatus de esa profesión u oficio, marcada por aspectos como la dificultad para las mujeres de acceder a cargos de dirección (England, et al., 2007; Lemos, Barufaldi y Nereida, 2015; Yannoulas, 2011). Dicha situación está determinada por una serie de estereotipos de género (Parra, 2017), los cuales son estudiados por Giraldo, Jaramillo, Torres y Gómez (2011) en las grandes empresas de Medellín.

Ahora bien, las reflexiones sobre el liderazgo femenino y lo que implica en la toma de decisiones se transforman en habilidades claves para la formación de contables, estas se basan en la premisa de que no hay estructuras plenamente definidas y evidencian modelos de liderazgo diferentes a los tradicionales (Forero, 2016; Rodríguez y Sepulveda, 2018). De igual forma, se halla el trabajo de Perafán (2018), el cual resalta la participación femenina en las juntas directivas de una muestra de empresas mexicanas, chilenas, peruanas y colombianas que cotizan en bolsa y que hacen parte del Mercado Integrado Latinoamericano [MILA], evidenciando que "entre más mujeres se sumen [...] mejor será la calidad de la información financiera de las empresas" (p. 152). En cuanto a los temas de ética, el estudio de González y Ramírez (2018) explora si el género es un factor determinante frente a los comportamientos fraudelentos en la profesión contable colombiana. En su estudio no se encontraron diferencias significativas entre hombres y mujeres, por el contrario, llegaron a la conclusión de que el fraude está 
determinado por lo que se conoce como "triángulo del fraude compuesto por presión, oportunidad y racionalización” (p. 20).

Desde otro punto de vista, se encuentran investigaciones que exploran las potencialidades de los estudios de género en lo contable a partir de revisiones relacionadas con la opresión femenina en los diferentes modos de producción (Rodríguez, 2014), o con las problemáticas de género en distintos contextos (Acosta, Patiño, Valero, Díaz, 2016). Estos estudios permiten evidenciar claramente los diferentes estereotipos de género, así como una división sexual del trabajo.

En conclusión, falta mucho por indagar y por hacer, desde lo contable, frente a los estudios de género y, en general, frente a las diferentes exclusiones que se han incubado en la sociedad, reflejadas también en el ejercicio profesional contable. Por tal razón, es necesario ampliar el rango de acción, de tal forma que se pueda estudiar lo que viene pasando con la comunidad LGTBI, la comunidad sorda, los raizales, las negritudes, es decir aquello que no es reconocido como heteronormativo en el marco de la disciplina y el ejercicio profesional. Finalmente, esta es una invitación a fortalecer los procesos de liderazgo femenino, de tal forma que se construyan amplios y fuertes espacios de sororidad ${ }^{1}$ entre contables, que permitan liderar lo que deseamos que sea la profesión y la disciplina contable desde esta otra mirada, la femenina; por ellos, es valioso resaltar cómo la Revista Activos busca ser un escenario para la divulgación de estos trabajos.

1 Sororidad es un concepto que se asocia a la hermandad entre mujeres, sin embargo, implica muchas más aristas que simplemente acompañar y apoyar "a la otra", en palabras de Martínez (2017) implica compartir "experiencias de mujeres que conducen a la búsqueda de relaciones positivas de empoderamiento y liderazgo de mujeres" (p. 50). 


\section{Referencias}

Acosta, M. G., Patiño, R. A., Valero, G. M. y Díaz, M. A. (2016). Las problemáticas de género: una introducción para su aplicación en estudios de contabilidad. Revista Activos, 13(25), 33-72. https://doi.org/10.15332/ s0124-5805.2015.0025.02

Bueno, A. M. y León, E. F. (2013). La perspectiva de género en profesiones feminizadas en Colombia. Caso: trabajo social y contaduría pública. En F. R. Arella, J. P. Borche, A. M. Bueno, E. F. León, C. G. López, G. Rotman, C. G. Lopez, A. R. (Comp.), Género y educación en la Economía Social. Siglos XX y XXI (pp. 30-45). Instituto de Estudios del Pensamiento y la Acción Solidaria.

Carmona, S., Ezzamel, M. y Mogotocor, C. (2018). Gender, Management Styles, and Forms of Capital. Journal of Business Ethics, Springer, 153(2), 357-373. https://doi.org/10.1007/s10551-016-3371-8

Chamorro, C. (2015). La participación de la mujer en el desarrollo de la Contaduría Pública en Colombia. Ponencia presentada a la Universidad de la Costa. https:// www.researchgate.net/publication/286381703_la_participacion_de_la_ mujer_en_el_desarrollo_de_la_contaduria_publica_en_colombia

Chamorro, C., Patiño, R. A. y Vásquez, L. (2020). Women Accountants in Academic and Research Spaces in Colombia. Advances in Public Interest Accounting, 22, 23-34. https://doi.org/10.1108/S1041-706020200000022002

England, P., Paul, A., Li, S., Mark, N., Thompson, J., Budig, M. J. y Sun, H. (2007). Why Are Some Academic Fields Tipping toward Female? The Sex Composition of U.S. Fields of Doctoral Degree Receipt, 1971-2002. Sociology of Education, 80(1). http://www.jstor.org/stable/20452693

Forero, S. (2016). Participación de la mujer profesional de la Contaduría Pública en cargos que implican alto liderazgo y toma de decisiones. https://repository. unimilitar.edu.co/handle/10654/14636

García, J. F., Valero, G. M., Sandoval, J. D. y Cortes, P. E. (2021, en prensa). Participación femenina en los procesos académicos de la profesión contrable. Una revisión documental. En G. M. Valero, R. A. Patiño, A. D. Díaz, J. F. García, J. D. Sandoval, M. G. Acosta, E. Gómez, Educación e investigación contable en Colombia. Una mirada holística de la disciplina. Fondo Editorial CEIPA, Business School. 
Giraldo, D. P., Jaramillo, E. M., Torres, Y. N. y Gómez, L. F. (2013). Influencia de los estereotipos de género en el área contable en las grandes empresas de Medellín. Contaduría Universidad De Antioquia, (58-59), 197-231. https:// revistas.udea.edu.co/index.php/cont/article/view/14636

González, D. C. y Ramírez, D. (2018). Características de los Contadores Públicos involucrados en temas de fraude en Colombia, desde la perspectiva de género, entre el año 2012 y el 2017. https://repository.usta.edu.co/ handle/11634/16727?show=full

Lemos, L., Barufaldi, R. y Nereida, S. (2015). La Feminización del Área Contable: un Estudio Cualitativo Básico. Revista de Educação e Pesquisa em Contabilidade, 9(1), 64-84. https://doi.org/10.17524/repec.v9i1.1159

López, E. J. (2018). Análisis del papel de las mujeres en la investigación contable desarrollada en el Departamento del Quindío desde una perspectiva de género. En-Contexto, 6(9), 157-180. https://ojs.tdea.edu.co/index.php/encontexto/ article/view/503

López, D. (2018). La mujer contadora en las publicaciones académicas en Colombia. http://vitela.javerianacali.edu.co/handle/11522/11294

Martínez, S. (2017). Procesos de empoderamiento y liderazgo de las mujeres a través de la sororidad y la creatividad. Dossiers Feministes, (22), 49-72. http:// dx.doi.org/10.6035/Dossiers.2017.22.4

Parra, J. (2017). ¿Existen razones medibles para pensar que existe una segregación ocupacional de género en la contaduría pública? https://repository.ucc.edu. co/bitstream/20.500.12494/13092/1/2019-Segregaci\%c3\%b3n-ocupacionalgenero-contaduria.pdf

Patiño, R. y Valero, G. (octubre de 2012). En Clave Femenina. La investigación contable colombiana. Trabajo presentado en la XIII Asamblea General de ALAFEC, Buenos Aires, Argentina. http://www.alafec.unam.mx/docs/asambleas/xiii/ ponencias/educacion/E_01.pdf

Patiño, R. A., Valero, G. M., Acosta, M. G. y Díaz, M. A. (2021, en prensa). Mujer: experiencias de investigadoras contables en Latinoamérica. En G. M. Valero, R. A. Patiño, A. D. Díaz, J. F. García, J. D. Sandoval, M. G. Acosta, ... E. Gómez, Educación e Investigación Contable en Colombia. Una mirada holística de la disciplina. Fondo Editorial CEIPA, Business School. 
Perafán, H. (2018). Board gender diversity and earnings quality. Evidence from the Latin American integrated market (MILA). Contaduría Universidad de Antioquia, 72, 151-163. https://doi.org/10.17533/udea.rc.n72a08

Restrepo, K. (2018). Diferencias salariales por género en la profesión contable en Colombia (2008-2012) (tesis de la Maestría en Estudios y Gestión del Desarrollo). https://ciencia.lasalle.edu.co/maest_gestion_desarrollo/142/

Restrepo, K. y Isaza, J. (2019). ¿De lo masculino a lo femenino? Reflexiones sobre el mercado laboral de la contaduría pública. Revista Científica General José María Córdova, 17(27), 527-533. http://dx.doi.org/10.21830/19006586.385

Rico, C. (2020). Making women visible in the (accounting) history of Colombia. Accounting History Review, 30(2), 207-232. https://doi.org/10.1080/2155285 1.2020 .1763410

Rodríguez, M. A. (2014). Mujeres, Las voces desobedientes de nuestra historia: notas para develar la potencialidad de los estudios de género en el ámbito contable. Adversia, (15). https://revistas.udea.edu.co/index.php/adversia/ article/view/20908

Rodríguez, A. J. y Sepulveda, L. (2018). Factor de mayor incidencia en la asignación de cargos gerenciales a contadores públicos según el género. Una revisión de la literatura (trabajo de grado para el pregrado de Contaduría Pública). http://hdl.handle.net/11371/3011

Santana, A. y Pastás, D. P. (2014). Participación de la mujer en la historia del programa académico de Contaduría Pública en la Universidad del Valle Sede Norte del Cauca. https://bibliotecadigital.univalle.edu.co/handle/10893/13463

Scott, J. (2008). Género e Historia. (1 ${ }^{\text {a }}$ ed.) (I. De Consol, trad.). México: Fondo de Cultura Económica, Universidad Autónoma de la Ciudad de México.

Yannoulas, S. (2011). Feminização ou Feminilização? Apontamentos em torno de uma categoria. Temporalis, (22), 271-292. https://dialnet.unirioja.es/servlet/ articulo? codigo $=4054571$

Valero, G., Patiño, R. y Vargas, H. (2020). Feminilización y Feminización de la Profesión Contable en Colombia. Contaduría Universidad de Antioquia, (76), 13-33. https://doi.org/10.17533/udea.rc.n76a01

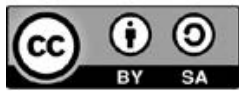

